Chronic Obstructive Pulmonary Diseases: Journal of the COPD Foundation

\author{
Original Research
}

\title{
Effect of Tiotropium on Outcomes in Patients With COPD, Categorized Using the New GOLD Grading System: Results of the UPLIFT ${ }^{\circledR}$ Randomized Controlled Trial
}

David M.G. Halpin, DPhil, FRCP ${ }^{1}$ Donald P. Tashkin, $\mathrm{MD}^{2}$ Bartolome R. Celli, $\mathrm{MD}^{3}$ Inge Leimer, $\mathrm{PhD}^{4}$ Norbert Metzdorf, $\mathrm{PhD}^{4}$ Marc Decramer, $\mathrm{MD}^{5}$

\begin{abstract}
A retrospective analysis of the Understanding Potential Long-term Impacts on Function with Tiotropium (UPLIFT ${ }^{\circledR}$ ) trial data was performed, grading patients by the 2013 Global initiative for chronic Obstructive Lung Disease (GOLD) severity groups. The number of antibiotics/systemic corticosteroids courses and hospitalizations/ emergency department (ED) visits for COPD in the preceding year, baseline forced expiratory volume in 1 second $\left(F_{1}\right)$ and St. George's Respiratory Questionnaire (SGRQ) score were used to grade patients: 357 (6.3\%), 1421 (24.9\%), 299 (5.2\%), and 3636 (63.7\%) in Groups A-D, respectively. Mean FEV1 was higher and SGRQ scores lower with tiotropium than usual care (control) in all GOLD groups at all post-baseline time points during treatment. In the control group, mean (95\% confidence interval [CI]) exacerbation rates per patient per year were highest in Group D (1.01 [0.96, 1.07]), similar in Groups B (0.63 [0.57, 0.69]) and C (0.72 [0.59, 0.87]), and lowest in Group A $(0.48$ [0.39, 0.59]). Tiotropium significantly prolonged time to first exacerbation versus control in Groups B and D (hazard ratios [95\% CI]: 0.79 [0.69, 0.91] and 0.89 [0.82, 0.96]); in Groups A and C, similar effects were observed, reflecting the small size of these groups. The number of exacerbations per patient-year was lower with tiotropium than control in all GOLD groups (rate ratios 0.64, 0.72, 0.91, and 0.89 for Groups A-D; $p<0.005$ for all but Group C ( $p=0.4978)$. The incidence rate of major adverse cardiac events was higher in Group $\mathrm{D}$ than in Groups A-C but lower within the group in patients treated with tiotropium. In conclusion, tiotropium improved lung function and health status, and reduced exacerbation rates in patients in all GOLD groups.
\end{abstract}

Abbreviations: Understanding Potential Long-term Impacts on Function with Tiotropium, UPLIFT ${ }^{\oplus}$; Global initiative for chronic

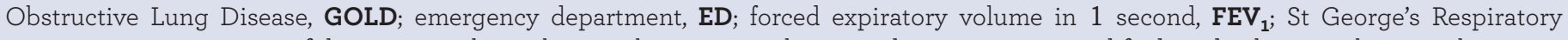
Questionnaire, SGRQ; confidence interval, CI; chronic obstructive pulmonary disease, COPD; modified Medical Research Council, mMRC; COPD Assessment Test, CAT; health-related quality of life, HRQoL; forced vital capacity, FVC; major adverse cardiac events, MACE; inhaled corticosteroids, ICS; long-acting $\beta 2$-agonists, LABA; rate ratio, RR; coronary artery disease, CAD; cardiovascular, CV; standard deviation, SD Funding Support: Funded jointly by Boehringer Ingelheim and Pfizer.

Date of Acceptance: April 13, 2014

Citation: Halpin DMG, Tashkin DP, Celli BR, Leimer I, Metzdorf N, Decramer M. Effect of tiotropium on outcomes in patients with COPD, categorized using the new GOLD grading system: Results of the UPLIFT randomized controlled trial. J COPD F. 2015; 236-251: doi: http://dx.doi.org/10.15326/jcopdf.2.3.2014.0142.

1 Royal Devon \& Exeter Hospital, Exeter, United Kingdom

2 David Geffen School of Medicine, University of California- Los Angeles
4 Boehringer Ingelheim, Ingelheim, Germany

5 University of Leuven, Belgium

3 Brigham and Women's Hospital, Boston, Massachusetts 


\section{Address correspondence to:}

Prof DMG Halpin

Consultant Physician and Honorary Associate Professor

Respiratory Clinical Lead, NHS SW

Royal Devon and Exeter Hospital

Barrack Road

Exeter, Devon

EX2 5DW

United Kingdom

Tel: +44 (0) 1392402133

Fax: +44 (0) 1392402828

Email: d.halpin@nhs.net

\section{Keywords:}

chronic obstructive pulmonary disease; COPD; bronchodilator; exacerbations; lung function; health status; quality of life

\section{Introduction}

Tiotropium is a once-daily, inhaled anticholinergic that provides at least 24 hours of improvement in airflow and hyperinflation in patients with COPD., ${ }^{1,2}$ The Understanding Potential Long-term Impacts on Function with Tiotropium (UPLIFT ${ }^{\circledR}$ ) trial was undertaken to assess the long-term efficacy and safety of tiotropium compared to placebo (control) with the primary outcome being the rate of decline in forced expiratory volume in 1 second $\left(\mathrm{FEV}_{1}\right)$ in patients with COPD (primary endpoint was not met). ${ }^{3}$ Patients in both groups were allowed to use other COPD medications, including short- and long-acting respiratory medications, but no other inhaled anticholinergics. Patients who participated in the UPLIFT ${ }^{\circledR}$ study were carefully observed over a period of 4 years.

In 2011, the Global initiative for chronic Obstructive Lung Disease (GOLD) published updated guidelines on the diagnosis, management, and prevention of chronic obstructive pulmonary disease (COPD), ${ }^{4}$ which were revised further in $2013 .^{5}$ One of the most significant changes was the introduction of a new combined assessment scheme that attempts to "assess the severity of the disease, including the severity of airflow obstruction, the impact on the patient's health status and the risk of future events (such as exacerbations, hospital admissions, or death)" in order to guide therapy. The scheme uses the degree of postbronchodilator $\mathrm{FEV}_{1}$ impairment and the frequency of exacerbations in the previous 12 months to assess risk, as well as the modified Medical Research Council (mMRC) dyspnea score $^{6}$ or COPD Assessment Test (CAT) score ${ }^{7}$ to assess symptoms. Four groups (A, B, C, and D) of patients are identified by this scheme. Recommendations for first choice, alternative choice, and other possible treatments for pharmacologic therapy ${ }^{5}$ have been made following assessment of patients using this scheme, although the clinical trials on which these recommendations were based did not grade patients using the new scheme and its cut-off points.

In the present work, we have performed a retrospective analysis of UPLIFT ${ }^{\oplus}$ trial data, grading patients into the GOLD groups A, B, C, and D (2013 update), to examine the effects of tiotropium compared to usual care on lung function, health status, and exacerbations according to these groupings.

\section{Methods}

We performed a post-hoc analysis of data collected during the UPLIFT ${ }^{\circledR}$ study (ClinicalTrials.gov number: NCT00144339). Details of the study design and results on the primary and secondary endpoints have been previously reported. ${ }^{3,8}$ All patients gave written informed consent. The study was approved by local ethical review boards and conducted in accordance with the Declaration of Helsinki.

\section{Study Design}

The UPLIFT ${ }^{\circledR}$ study was a 4-year, randomized, doubleblind, placebo-controlled, parallel-group trial in patients with COPD. The primary endpoints were the yearly rate of decline of pre- and postbronchodilator $\mathrm{FEV}_{1}$ until completion of the double-blind treatment period. Secondary outcomes included other lung function measures, health-related quality of life (HRQoL) as measured by the St. George's Respiratory Questionnaire (SGRQ) total score, COPD exacerbations, and related hospitalizations, as well as safety and mortality.

Patients were recruited from 490 investigational centers in 37 countries. Criteria for participation included diagnosis of COPD, aged $\geq 40$ years, smoking history of $\geq 10$ pack years, and postbronchodilator $F E V_{1}$ $\leq 70 \%$ of the predicted normal value and $\mathrm{FEV}_{1} \leq 70 \%$ of forced vital capacity (FVC). Postrandomization clinic visits occurred at 1 and 3 months, and then every 3 months throughout the 4-year treatment period.

The treatment arms were tiotropium $18 \mu \mathrm{g}$ once daily or matching placebo (control), delivered via the HandiHaler ${ }^{\circledR}$ inhalation device (Boehringer Ingelheim Pharma GmbH and Co KG, Ingelheim, Germany). All respiratory medications other than inhaled anticholinergics were permitted during the trial. At 4 
years (approximately Day 1440), all patients were asked to stop the trial drug and were instructed to take openlabel ipratropium, 2 actuations $(40 \mu \mathrm{g}) 4$ times daily, and then to return for a final assessment after a 30-day study drug termination (approximately Day 1470), defined as the washout period.

\section{Spirometry}

Spirometry was performed according to American Thoracic Society guidelines: ${ }^{9}$ at randomization, at 30 days, and every 6 months throughout the treatment period; then at a follow-up visit approximately 30 days after the end of study treatment. The study drug was administered immediately after prebronchodilator spirometry and just before short-acting bronchodilator administration. All study sites were provided with identical spirometry equipment and study-specific software. A centralized quality assurance review of all spirometry data was performed during the study. ${ }^{8}$

\section{St. George's Respiratory Questionaire}

Patients were not assessed using the mMRC dyspnea scale nor the CAT test, but they did complete the SGRQ health status questionnaire. Jones et $\mathrm{al}^{10}$ have shown that there is a tight correlation between SGRQ and CAT scores $(\mathrm{r}=0.84 ; p<0.001)$. The regression equation for the relationship was: CAT score $=1.54+0.36 \times$ SGRQ. Thus, a CAT score of 10 corresponds to an SGRQ of 23.5; but there is considerable scatter in the relationship and, for this analysis, we have used an SGRQ score of 25 as an alternative for the GOLD symptom threshold CAT score of 10 .

\section{Exacerbations}

Exacerbations were defined as an increase in, or the new onset of, $>1$ respiratory symptom (cough, sputum, sputum purulence, wheezing, or dyspnea) lasting $\geq 3$ days and requiring treatment with an antibiotic or a systemic corticosteroid. Moderate exacerbations were defined as those requiring a health care provider visit (e.g., home visit or a visit to an outpatient facility or emergency department [ED]) but not requiring hospital admission). Data regarding exacerbations and related hospitalizations were collected on study-specific casereport forms at every visit. Two recorded exacerbation events separated by less than 7 days were considered as 1 single event. At study entry, patients also reported the number of courses of antibiotics or systemic corticosteroid treatment for breathing problems that they had received in the previous 12 months, as well as the number of hospitalizations and $E D$ visits for COPD in the previous 12 months.

\section{Grading of Patients into GOLD Groups}

Using the baseline postbronchodilator $\mathrm{FEV}_{1}$ values, SGRQ scores and reported exacerbation frequency over the preceding 12 months, patients randomized into the UPLIFT $^{\circledast}$ study were retrospectively graded into the GOLD groups as follows: Group A, fewer symptoms (SGRQ total score at baseline $<25$ ) and low risk (defined as postbronchodilator $\mathrm{FEV}_{1} \geq 50 \%$ and $\leq 1$ course of antibiotics, $\leq 1$ course of systemic corticosteroids and no COPD-related hospitalization); Group B, more symptoms (SGRQ total score at baseline $\geq 25$ ) and low risk (postbronchodilator $\mathrm{FEV}_{1} \geq 50 \%$ and $\leq 1$ course of antibiotics, $\leq 1$ course of systemic corticosteroids and no COPD-related hospitalization); Group C, fewer symptoms (SGRQ total score at baseline <25) and high risk (defined as postbronchodilator $\mathrm{FEV}_{1}<50 \%$ or $>1$ course of antibiotics or $>1$ course of systemic corticosteroids or $\geq 1$ COPD-related hospitalization); Group D, more symptoms (SGRQ total score at baseline $\geq 25$ ) and high risk (postbronchodilator $\mathrm{FEV}_{1}<50 \%$ or $>1$ course of antibiotics or $>1$ course of systemic corticosteroids or $\geq 1$ COPD-related hospitalization).

\section{Safety Analysis}

Major adverse cardiac events (MACE) were recorded in the UPLIFT ${ }^{\circledR}$ study and were analysed across the GOLD groups A-D.

\section{Statistical Analysis}

Time to first exacerbation was compared between treatment groups using log-rank tests, and Cox regression was used to derive hazard ratios separately for each of the GOLD A-D subgroups. To obtain the GOLD group-treatment interaction $p$-value, a subgroup-treatment interaction term was added to the model. Kaplan-Meier curves of the probability of no exacerbation were calculated and displayed together with the results of the log-rank test. Number of events was compared between treatment groups using Poisson regression, including the factors subgroup and subgroup-by-treatment interaction, with correction for treatment exposure and over dispersion.

Forced expiratory volume in 1 second, FVC values, and SGRQ total score were compared between treatment groups separately for each of the GOLD A-D subgroups 
using repeated-measures analysis of covariance without imputation of missing values with fixed, categorical effects of treatment subgroup, month, treatment-bymonth interaction, as well as the continuous, fixed covariates of baseline score and baseline score-byvisit interaction. To obtain the subgroup-by-treatment interaction $p$-value, a subgroup-by-treatment interaction term was added to the model. All reported $p$-values are 2-sided and not adjusted for multiple testing.

A sensitivity analysis was performed to demonstrate the effects of using different cut-offs in the SGRQ total score on the split between GOLD groups with fewer/ more symptoms ( $A / B$, and $C / D$, respectively).

Deaths (fatal adverse events), fatal MACE and MACE data by GOLD group were summarized using descriptive statistics (number and percentage of patients; incidence rate per 100 patient years).

\section{Results}

\section{Study Population}

Data were available for 5713 of the 5992 patients randomized and treated in the UPLIFT ${ }^{\circledR}$ trial to allow for classification into GOLD Groups A, B, C, and D. Of these, 357 (6.2\%) were in GOLD Group A, 1421 (24.9\%) were in Group B, 299 (5.2\%) were in Group C, and 3636 (63.6\%) were in Group D.

Patient baseline characteristics are shown in Table 1. Although classified on the basis of higher SGRQ scores, patients in Group D also had lower mean FEV 1 than those in Group C, but there was no difference in lung function between Groups A and B. In all, 30.4\% of patients in Group C and $21.7 \%$ of patients in Group D had $\mathrm{FEV}_{1} \geq 50 \%$ predicted and were classified as high risk based on exacerbation history only.

The proportions of patients receiving inhaled anticholinergics and inhaled and oral corticosteroids at baseline are also shown in Table 1. Overall, 171 patients (47.9\%) in Group A, 777 (54.7\%) in Group B, 192 (64.2\%) in Group C, and 2401 (66.0\%) in Group D were receiving inhaled corticosteroids (ICS) at baseline; 127 patients (35.6\%) in Group A, 592 (41.78\%) in Group B, 152 (50.8\%) in Group C, and 1915 (52.7\%) in Group $D$ were receiving a combination of ICS and long-acting $\beta 2$-agonists (LABA), either as separate components or as a fixed-dose combination (Table 1).

There was minimal difference between the groups in the proportion of patients with any cardiac disorder, including coronary artery disease, or the proportion receiving cardiovascular medication (Table 1).

By the end of the study, a total of 2344 patients had discontinued. Of these, 74 (3.2\%) patients in Group A had discontinued (39 [3.7\%] in the tiotropium group and 35 [2.7\%] in the control group), 471 (20.1\%) in Group B (223 [21.3\%] in the tiotropium group and 248 [19.1\%] in the control group), 94 (4.0\%) in Group C (46 [4.4\%] in the tiotropium group and 48 [3.7\%] in the control group), and 1705 (72.7\%) in Group D (739 [70.6\%] in the tiotropium group and 966 [74.5\%] in the control group).

\section{Lung Function}

Mean values of prebronchodilator FEV1 were consistently higher with tiotropium than control in all GOLD groups at all post-baseline time points during the trial, with differences by Year 4 of $160 \mathrm{~mL}$ for Group A (95\% CI: 110, 210; $p<0.0001), 90 \mathrm{~mL}$ for Group B (95\% CI: 59, 122; $p<0.0001), 100 \mathrm{~mL}$ for Group C (95\% CI: 30, 162; $p=0.0046$ ) and $80 \mathrm{~mL}$ for Group D (95\% CI: 63, 104; $p<0.0001)$ (Figure 1). Over the course of the study, between-treatment group differences in prebronchodilator $F E V_{1}$ ranged from 110 to $180 \mathrm{~mL}$ in Group A, 90 to $120 \mathrm{~mL}$ in Group B, 100 to $150 \mathrm{~mL}$ in Group C, and 80 to $100 \mathrm{~mL}$ in Group D (Figure 1). The $p$-value for treatment-subgroup interaction term was 0.0196. For the postbronchodilator FEV1 (after inhalation of salbutamol plus ipratropium in both groups), differences between treatment groups ranged from 70 to $140 \mathrm{~mL}$ in Group A, 50 to $70 \mathrm{~mL}$ in Group B, 50 to $110 \mathrm{~mL}$ in Group C, and 40 to $60 \mathrm{~mL}$ in Group D (treatment subgroup interaction $p$-value: 0.1503 ) (Figure 1).

Prebronchodilator FVC improved significantly for patients receiving tiotropium versus control, with differences by Year 4 of $210 \mathrm{~mL}$ for Group A (95\% CI: $115,314 ; p<0.0001), 170 \mathrm{~mL}$ for Groups B (95\% CI: 112,$222 ; p<0.0001)$ and D (95\% CI: 127,216 ; $p<0.0001)$, and $200 \mathrm{~mL}$ for Group C (95\% CI: 75, 321; $p=0.0017$ ) (Figure 2). Differences between the tiotropium and control groups in prebronchodilator FVC throughout the study duration ranged from 170 to $250 \mathrm{~mL}$ in Group A, 160 to $200 \mathrm{~mL}$ in Group B, 180 to $310 \mathrm{~mL}$ in Group C, and 170 to $220 \mathrm{~mL}$ in Group D. The model including the treatment-subgroup interaction term showed a non-significant interaction ( $p=0.4644)$ (Figure 2). Differences in postbronchodilator FVC throughout the study duration ranged from 30 to 100 $\mathrm{mL}$ in Group A, 30 to $60 \mathrm{~mL}$ in Group B, 10 to $110 \mathrm{~mL}$ 


\section{Table 1. Baseline Characteristics of Patients in the UPLIFT ${ }^{\circledR}$ Trial, $^{-}$ Classified According to GOLD Groups and Treatment Allocation}

\begin{tabular}{|c|c|c|c|c|c|c|c|c|}
\hline \multirow{2}{*}{$\begin{array}{l}\text { GOLD Group } \\
\text { Treatment Group }\end{array}$} & \multicolumn{2}{|c|}{$\mathbf{A}$} & \multicolumn{2}{|c|}{$\mathbf{B}$} & \multicolumn{2}{|c|}{ C } & \multicolumn{2}{|c|}{ D } \\
\hline & Tiotropium & Control & Tiotropium & Control & Tiotropium & Control & Tiotropium & Control \\
\hline Number of pa & 188 & 169 & 693 & 728 & 151 & 148 & 1816 & 1820 \\
\hline Age, years ${ }^{a}$ & $65.6 \pm 8.3$ & $64.2 \pm 8.4$ & $64.6 \pm 8.5$ & $64.7 \pm 8.5$ & $64.1 \pm 8.4$ & $65.0 \pm 8.0$ & $64.5 \pm 8.4$ & $64.5 \pm 8.5$ \\
\hline Male, n (\%) & $155(82.4)$ & $136(80.5)$ & $504(72.7)$ & $530(72.8)$ & $134(88.7)$ & $123(83.1)$ & $1345(74.1)$ & $1317(72.4)$ \\
\hline Current smokers, n (\%) & $52(27.7)$ & $53(31.4)$ & $240(34.6)$ & $248(34.1)$ & $36(23.8)$ & 35 (23.6) & $512(28.2)$ & $517(28.4)$ \\
\hline \multicolumn{9}{|l|}{ Prebronchodilator ${ }^{\mathrm{a}}$} \\
\hline $\mathrm{FEV}_{1}, \mathrm{~L}$ & $1.46 \pm 0.38$ & $1.43 \pm 0.30$ & $1.36 \pm 0.37$ & $1.36 \pm 0.35$ & $1.11 \pm 0.34$ & $1.11 \pm 0.34$ & $0.96 \pm 0.34$ & $0.95 \pm 0.35$ \\
\hline $\mathrm{FEV}_{1}, \%$ pred. & $51.4 \pm 7.7$ & $49.8 \pm 7.4$ & $48.6 \pm 8.3$ & $48.7 \pm 8.2$ & $38.5 \pm 10.8$ & $39.1 \pm 10.1$ & $34.8 \pm 10.7$ & $34.4 \pm 10.7$ \\
\hline FVC, L & $3.05 \pm 0.86$ & $3.08 \pm 0.78$ & $2.92 \pm 0.82$ & $2.94 \pm 0.83$ & $2.65 \pm 0.75$ & $2.68 \pm 0.76$ & $2.47 \pm 0.76$ & $2.45 \pm 0.79$ \\
\hline FVC, \% pred. & $84.8 \pm 16.1$ & $84.6 \pm 16.4$ & $83.0 \pm 16.5$ & $83.3 \pm 15.0$ & $71.8 \pm 17.6$ & $74.0 \pm 16.3$ & $71.0 \pm 17.5$ & $70.8 \pm 18.0$ \\
\hline $\mathrm{FEV}_{1} / \mathrm{FVC}$ & $0.49 \pm 0.09$ & $0.48 \pm 0.09$ & $0.48 \pm 0.10$ & $0.47 \pm 0.09$ & $0.43 \pm 0.10$ & $0.42 \pm 0.09$ & $0.40 \pm 0.10$ & $0.39 \pm 0.10$ \\
\hline \multicolumn{9}{|l|}{ Postbronchodilator ${ }^{a}$} \\
\hline $\mathrm{FEV}_{1}, \mathrm{~L}$ & $1.72 \pm 0.38$ & $1.73 \pm 0.34$ & $1.63 \pm 0.37$ & $1.63 \pm 0.36$ & $1.34 \pm 0.38$ & $1.33 \pm 0.37$ & $1.17 \pm 0.38$ & $1.14 \pm 0.38$ \\
\hline $\mathrm{FEV}_{1}, \%$ pred. & $0.7 \pm 5.5$ & $60.0 \pm 6.3$ & $58.6 \pm 5.7$ & $58.6 \pm 5.7$ & 46.3 & $46.7 \pm 10.7$ & $42.2 \pm 11.5$ & $41.6 \pm 11.1$ \\
\hline \multicolumn{9}{|l|}{ GOLD Stage, n (\%) } \\
\hline I & $0(0.0)$ & $1(0.6)$ & $0(0.0)$ & $0(0.0)$ & $0(0.0)$ & $0(0.0)$ & $2(0.1)$ & $0(0.0)$ \\
\hline II & $188(100)$ & $168(99.4)$ & $728(100)$ & $693(100)$ & $42(27.8)$ & $47(31.8)$ & $397(21.9)$ & $348(19.1)$ \\
\hline III & $0(0.0)$ & $0(0.0)$ & $0(0.0)$ & $0(0.0)$ & $100(66.2)$ & $96(64.9)$ & $1165(64.2)$ & $1198(65.8)$ \\
\hline IV & $0(0.0)$ & $0(0.0)$ & $0(0.0)$ & $0(0.0)$ & $8(5.3)$ & $4(2.7)$ & $232(12.8)$ & $252(13.8)$ \\
\hline SGRQ total & 16.59 & 17.07 & 44.57 & 44.81 & 18.09 & 18.50 & 50.83 & 50.62 \\
\hline Anticholinergic use, n (\%) & $52(27.7)$ & $55(32.5)$ & $283(40.8)$ & $286(39.3)$ & $62(41.1)$ & $63(42.6)$ & $935(51.5)$ & $915(50.3)$ \\
\hline LABA use, $n(\%)$ & $83(44.1)$ & $78(46.2)$ & $356(51.4)$ & $386(53.0)$ & $91(60.3)$ & $86(58.1)$ & $1167(64.3)$ & $1163(63.9)$ \\
\hline ICS use, $\mathrm{n}(\%)$ & $91(48.4)$ & $80(47.3)$ & 377 (54.4) & $400(54.9)$ & $94(62.3)$ & $98(66.2)$ & $1195(65.8)$ & $1206(66.3)$ \\
\hline ICS + LABA use, $n(\%)^{b}$ & $66(35.1)$ & $61(36.1)$ & $288(41.6)$ & $304(41.8)$ & 75 (49.7) & 77 (52.0) & $961(52.9)$ & $954(52.4)$ \\
\hline Other steroid use, n (\%) & $6(3.2)$ & $3(1.8)$ & $27(3.9)$ & $39(5.4)$ & $8(5.3)$ & $6(4.1)$ & $207(11.4)$ & $195(10.7)$ \\
\hline Cardiac disorders, \% & 24.5 & 21.9 & 24.2 & 23.5 & 23.8 & 16.9 & 28.2 & 27.3 \\
\hline $\mathrm{CAD}, \%$ & 12.8 & 13.6 & 16.7 & 15.8 & 15.2 & 11.5 & 17.0 & 16.0 \\
\hline Hypertension, \% & 38.3 & 43.2 & 43.3 & 45.5 & 43.7 & 37.8 & 40.5 & 41.0 \\
\hline Arrhythmias, \% & 6.9 & 4.1 & 6.2 & 5.5 & 6.6 & 4.1 & 7.6 & 7.4 \\
\hline CV medication use, \% & 52.1 & 52.1 & 55.4 & 56.5 & 58.3 & 52.0 & 57.7 & 55.5 \\
\hline
\end{tabular}

${ }^{a}$ Mean \pm SD. ${ }^{b}$ Fixed or free combination.

CAD: coronary artery disease; $\mathrm{CV}$ : cardiovascular; $\mathrm{FEV}_{1}$ : forced expiratory volume in 1 second; FVC: forced vital capacity; GOLD: Global initiative for chronic Lung Disease; ICS: inhaled corticosteroid; LABA: long-acting $\beta$ 2-agonist; pred: predicted; SD: standard deviation; SGRQ: St.George’s Respiratory Questionnaire; UPLIFT ${ }^{\oplus}$ : Understanding Potential Long-term Impacts on Function with Tiotropium.

in Group C, and 40 to $80 \mathrm{~mL}$ in Group D. Also, here the investigation of the GOLD group*treatment interaction showed no significance $(p=0.8806)$ (Figure 2$)$.

\section{Health Status}

In the fewer-symptom groups (A and C), SGRQ scores increased (worsened) progressively from baseline, but less so in patients treated with tiotropium; conversely, in Groups B and D, SGRQ total scores decreased (improved) relative to baseline within the first 6 months (Figure 3). Differences in SGRQ scores between patients treated with tiotropium compared to the control groups 


\section{Figure 1. Estimates of Pre and Postbronchodilator Mean FEV 1}

$$
\begin{aligned}
& \text { Prebronchodilator mean FEV, } \\
& -\bigcirc-\text { Control } \\
& -\square-\text { Tiotropium } 18 \mu \mathrm{g}
\end{aligned}
$$

\section{GOLD A patients}

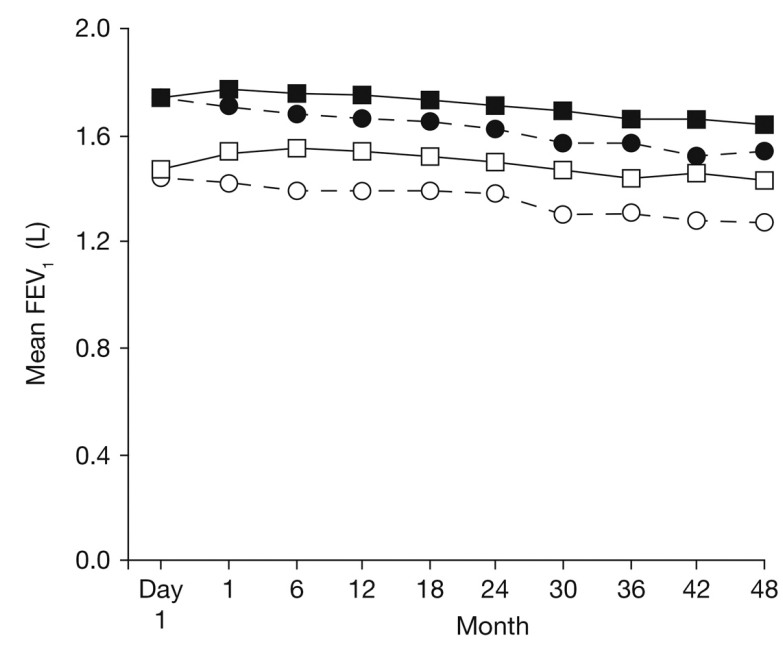

GOLD C patients

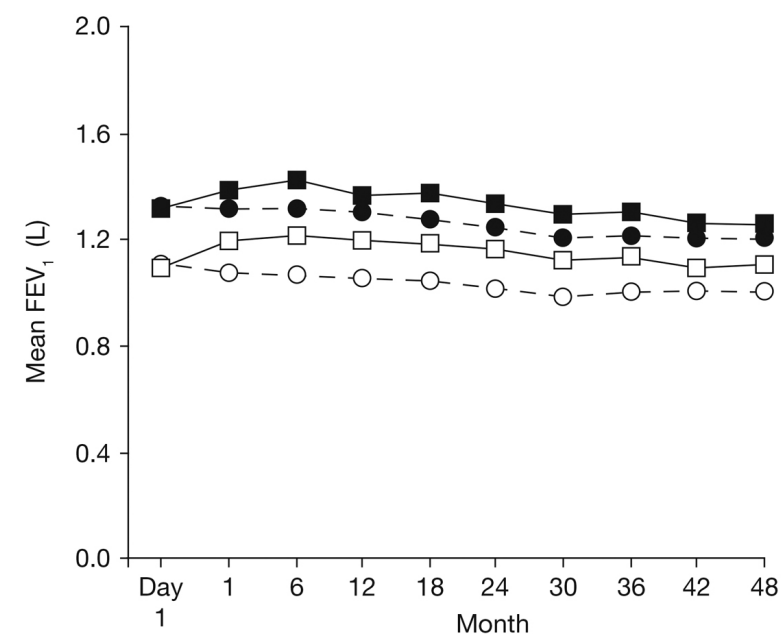

Postbronchodilator mean FEV

- - - Control
- - Tiotropium $18 \mu \mathrm{g}$

\section{GOLD B patients}

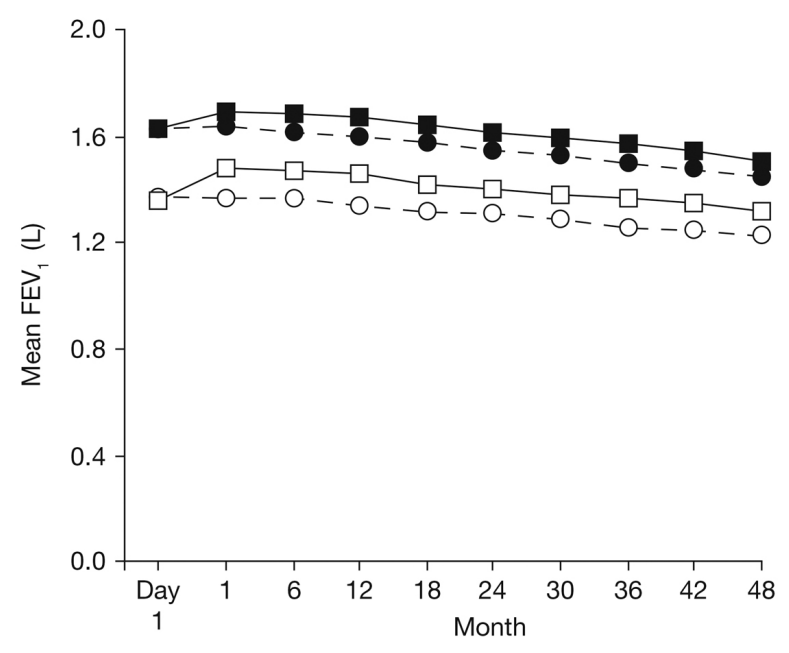

GOLD D patients

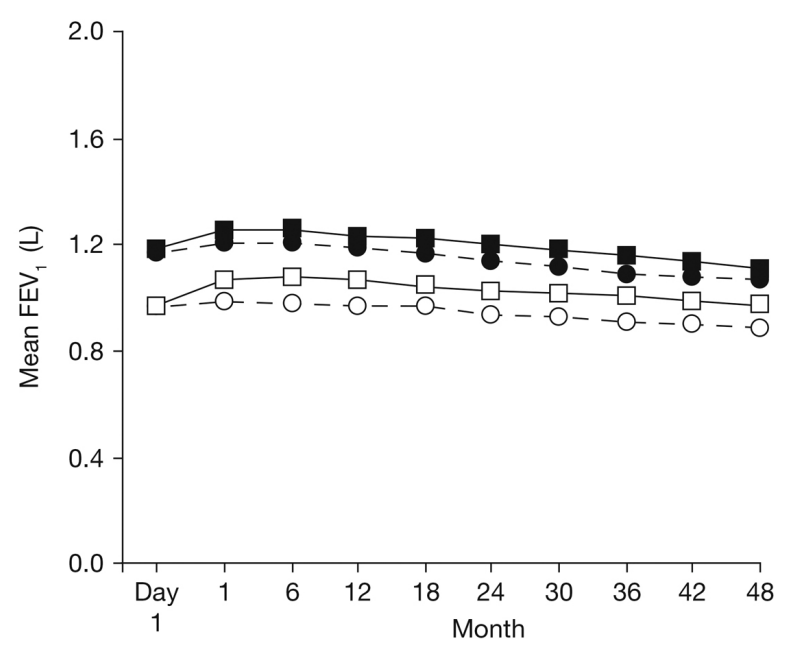

$\mathrm{FEV}_{1}$ : forced expiratory volume in 1 second; GOLD: Global initiative for chronic Obstructive Lung Disease

ranged from 1.29 to 3.12 ( $p \leq 0.05$ at all time points except at 12, 36 and 48 months) in Group A, 2.71 to 4.36 ( $p \leq 0.001$ at all time points) in Group B, 1.68 to 3.70 ( $p<0.05$ at $12,18,24$ and 36 months) in Group C, and 1.73 to 3.08 ( $p<0.01$ at all time points) in Group $\mathrm{D}$ (treatment subgroup interaction $p$-value: 0.6484). Improvements $(95 \% \mathrm{CI})$ in SGRQ total scores for tiotropium compared with control by Year 4 were -1.33 $(-4.22,1.56),-4.03(-5.89,-2.18),-2.46(-6.44$, 1.52), and $-1.73(-3.02,-0.44)$ for GOLD Groups A, B, $C$, and $\mathrm{D}$, respectively. The differences were all in favor of tiotropium throughout the course of the trial.

A sensitivity analysis was performed to examine the effects of using different cut-offs in the SGRQ total score 


\section{Figure 2. Estimates of Pre and Postbronchodilator Mean FVC}

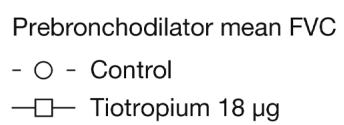

GOLD A patients

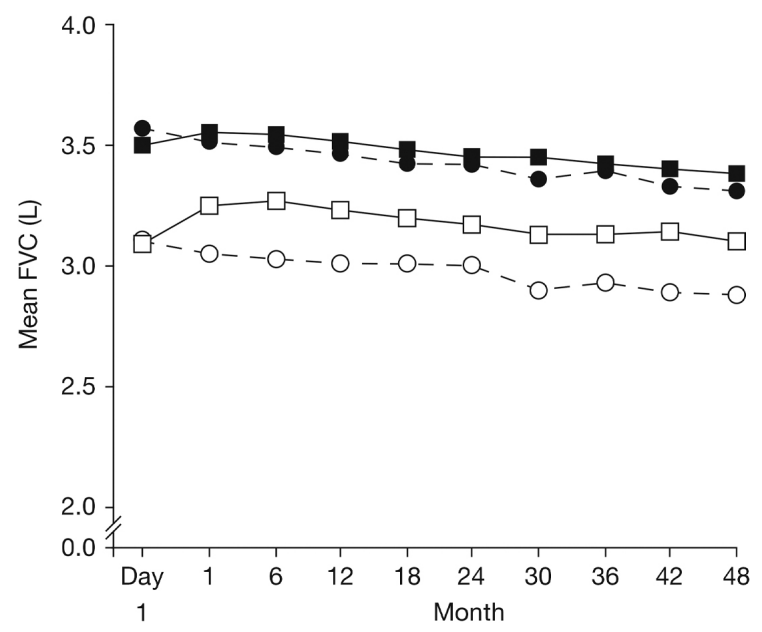

GOLD C patients

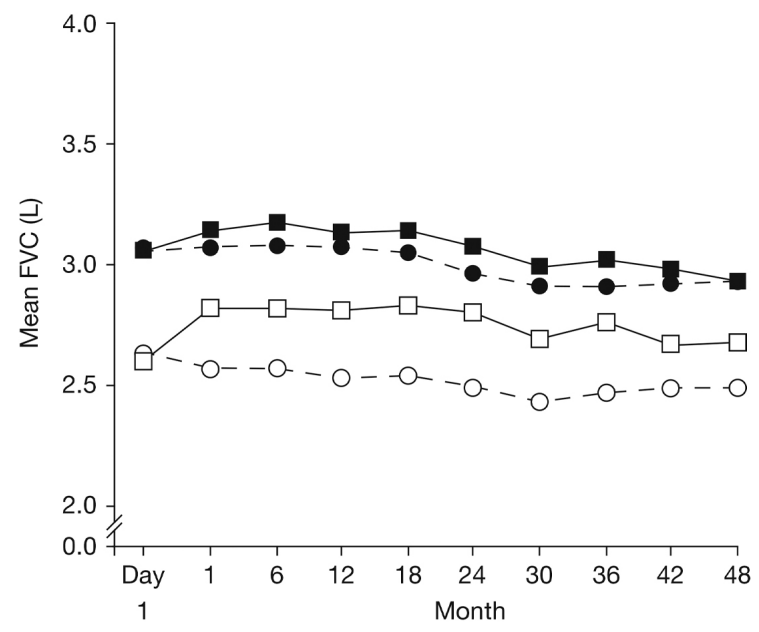

Postbronchodilator mean FVC

- - Control
$\square-$ Tiotropium $18 \mu \mathrm{g}$

\section{GOLD B patients}

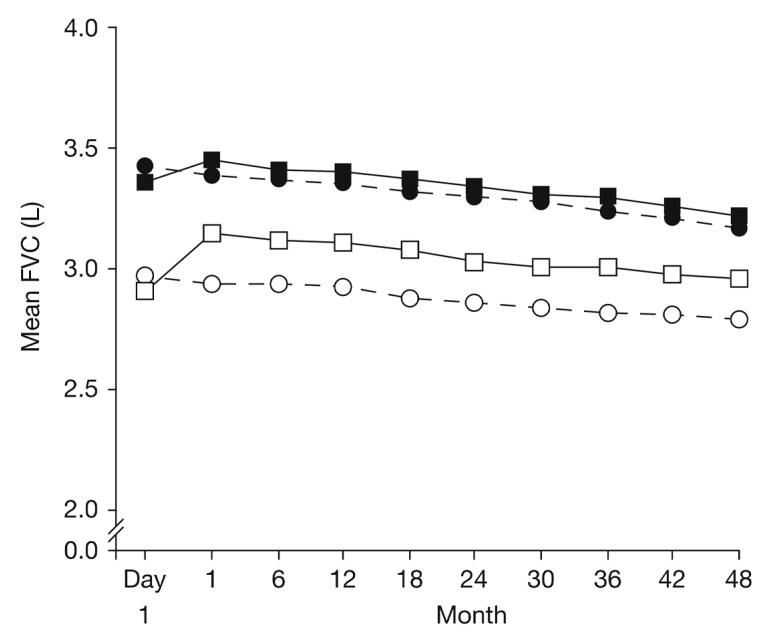

GOLD D patients

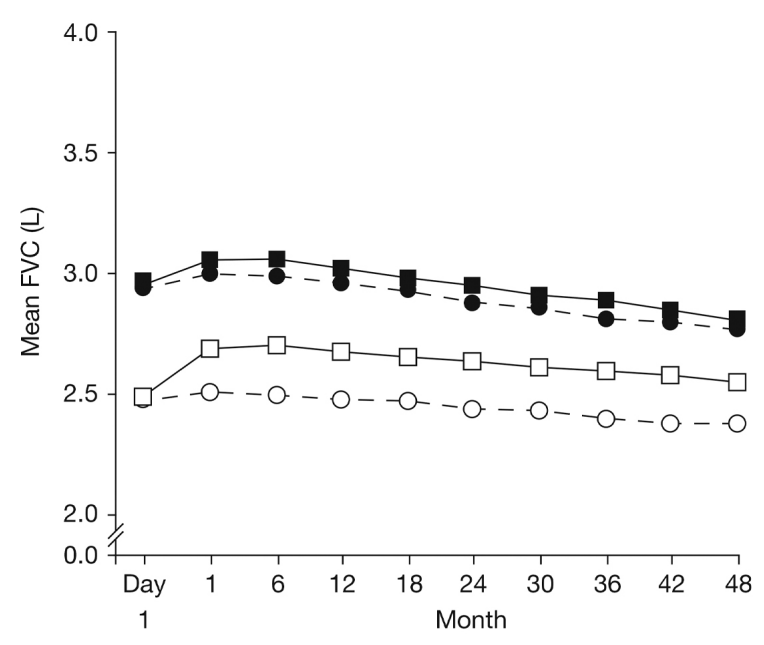

FVC: forced vital capacity; GOLD: Global initiative for chronic Obstructive Lung Disease

(between 20 and 50) on the distribution of patients among the GOLD groups (Figure 4). As patients with more symptoms (Groups B and D) generally had a higher SGRQ score, increases in the cut-off value had a greater impact on the relative proportion of patients in Groups A and C (who had fewer symptoms), particularly if low risk (Group A).

\section{Exacerbations}

Table 2 shows the numbers and rates of exacerbations in patients in GOLD Groups A-D. The proportion of patients who experienced at least 1 exacerbation was lower in Groups A and B than in Groups C and D. The number of exacerbations per patient-year was lower in the tiotropium group than in the control group in all GOLD groups and these differences were significant, 


\section{Figure 3. SGRQ Total Score Over the 4-year UPLIFT ${ }^{\circledR}$ Trial Period by GOLD Group}

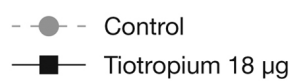

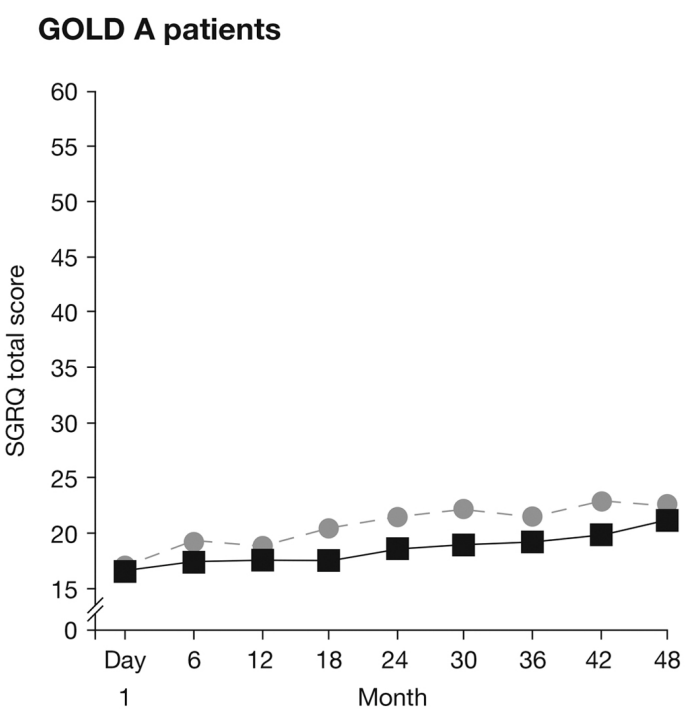

\section{GOLD B patients}

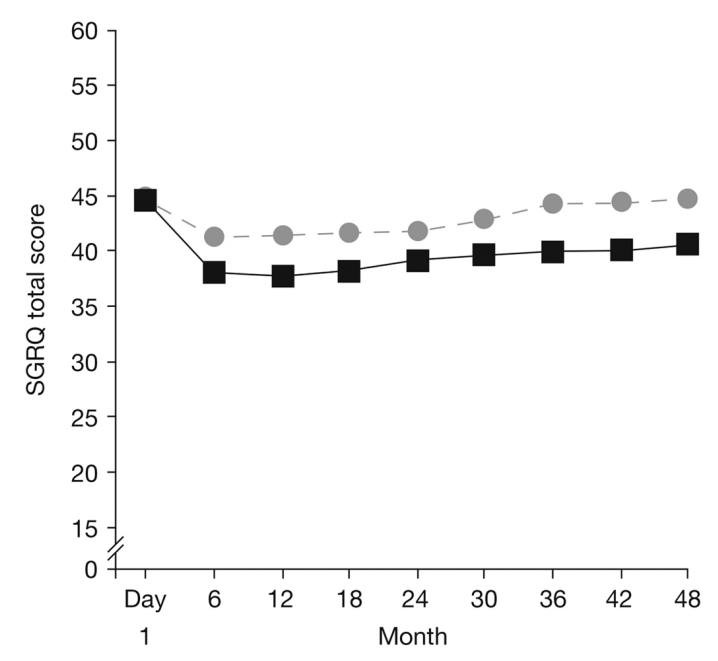

\section{GOLD D patients}

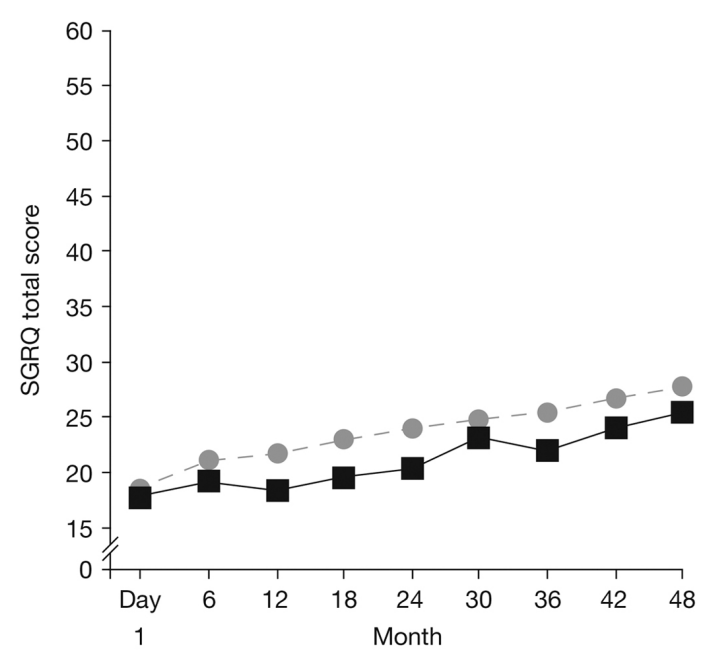

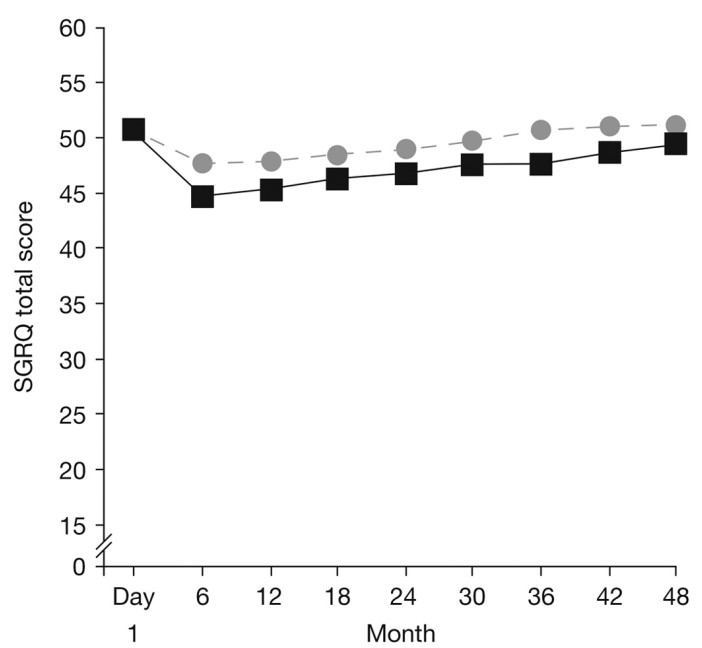

GOLD: Global initiative for chronic Obstructive Lung Disease; SGRQ: St. George’s Respiratory Questionnaire; UPLIFT ${ }^{\circledR}$ Understanding Potential Long-term Impacts on Function with Tiotropium

except in Group C (treatment subgroup interaction $p$-value: 0.0250).

Tiotropium prolonged the time to first COPD exacerbation compared to control, with a consistently reduced exacerbation risk across all GOLD groups (Figure 5); the $p$-values from the log-rank test for tiotropium versus control were 0.0765, 0.0007,
0.1687, and 0.0018 for Groups A, B, C, and D, respectively. Hazard ratios (95\% CI) from the Cox regression were $0.77(0.58,1.03), 0.79(0.69,0.91)$, $0.82(0.63,1.09)$, and 0.89 (0.82, 0.96), p-values were very similar to those from the log-rank test. The model containing the treatment-subgroup interaction term showed no significant interaction $(p=0.5231)$. 
Statistical significance was reached in Groups B and D in which patient numbers were highest.

\section{Safety Analysis}

Rates of death (fatal adverse events) and fatal MACE are shown in Table 3. The incidence of death was highest in
GOLD Group D (rate per 100 patient years, 5.08 with tiotropium and 6.06 with control) and lowest in Group A (rate per 100 patient years, 1.92 with tiotropium and 1.87 with control). Rates of death, fatal MACE overall, and fatal myocardial infarction were significantly lower with tiotropium than control in Group D (rate ratio

\section{Figure 4. Results of the Sensitivity Analysis Using Different Cut-Offs in SGRQ Total Score}

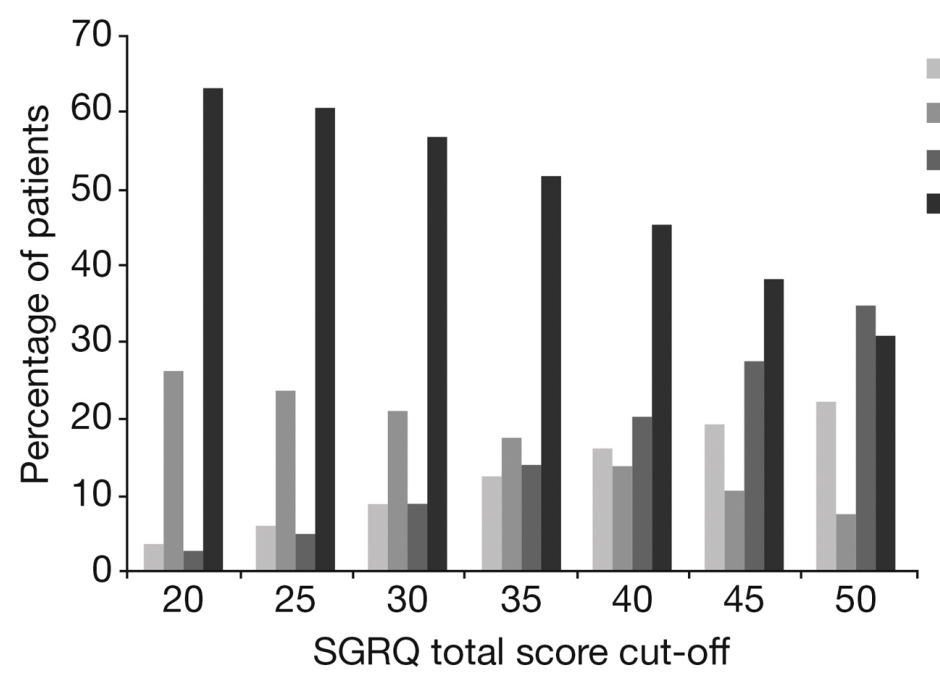

[RR] (95\% CI) 0.84 (0.71, 0.99), 0.70 (0.51, 0.96), and $0.36(0.15,0.88)$, respectively). No cardiac deaths were reported in GOLD Groups A-C but one cardiac death occurred in group $\mathrm{D}$ (control).

GOLD group A A similar pattern of results was seen - GOLD group B for the incidence of MACE (Table GOLD group C 4). The rate per 100 patient years - GOLD group D was highest in Group D (2.80 with tiotropium and 3.52 with control) and lowest in Group A (1.66 with tiotropium and 2.11 with control). In Group D, there was a significant difference in favor of tiotropium for rates of MACE overall and rates of myocardial infarction (RR [95\% CI] versus control, 0.79 [0.64, 0.99] and 0.68 [0.48, 0.98], respectively). Rates of fatal MACE and MACE were similar in the tiotropium and control groups across GOLD groups A-C.

GOLD: Global initiative for chronic Obstructive Lung Disease; SGRQ: St.George's Respiratory Questionnaire

\section{Table 2. Numbers and Rates of COPD Exacerbations by GOLD Group}

\begin{tabular}{|c|c|c|c|c|c|c|c|c|}
\hline & \multicolumn{3}{|c|}{ Tiotropium } & \multicolumn{3}{|c|}{ Control } & \multicolumn{2}{|c|}{$\begin{array}{c}\text { Tiotropium versus } \\
\text { Control }\end{array}$} \\
\hline & $\mathbf{N}$ & $\begin{array}{l}\mathrm{n} \text { with } \\
\text { event }\end{array}$ & $\begin{array}{l}\text { Rate of events }{ }^{a} \\
\quad(95 \% \mathrm{Cl})\end{array}$ & $\mathrm{N}$ & $\begin{array}{l}\mathrm{n} \text { with } \\
\text { event }\end{array}$ & $\begin{array}{l}\text { Rate of events }{ }^{a} \\
\quad(95 \% \mathrm{Cl})\end{array}$ & $\mathrm{RR}(95 \% \mathrm{Cl})$ & $p$-value \\
\hline \multicolumn{9}{|c|}{ GOLD Group } \\
\hline A & 188 & 91 & $0.31(0.24,0.40)$ & 169 & 92 & $0.48(0.39,0.59)$ & $0.64(0.47,0.89)$ & 0.0075 \\
\hline B & 693 & 386 & $0.45(0.41,0.51)$ & 728 & 453 & $0.63(0.57,0.69)$ & $0.72(0.62,0.83)$ & $<0.0001$ \\
\hline C & 151 & 99 & $0.65(0.54,0.80)$ & 148 & 104 & $0.72(0.59,0.87)$ & $0.91(0.69,1.20)$ & 0.4978 \\
\hline $\mathrm{D}$ & 1816 & 1332 & $0.90(0.85,0.95)$ & 1820 & 1300 & $1.01(0.96,1.07)$ & $0.89(0.83,0.95)$ & 0.0009 \\
\hline
\end{tabular}

Only exacerbations with onset during actual treatment were counted.

Interaction $P$-value: 0.0205 .

${ }^{a}$ Adjusted rate of events per patient-year.

CI: confidence interval; COPD: chronic obstructive pulmonary disease;

GOLD: Global initiative for chronic Obstructive Lung Disease; RR: rate ratio 


\section{Figure 5. Kaplan-Meier Curves of Time to First COPD Exacerbation in Patients From the UPLIFT ${ }^{\circledR}$ Trial by GOLD Group}
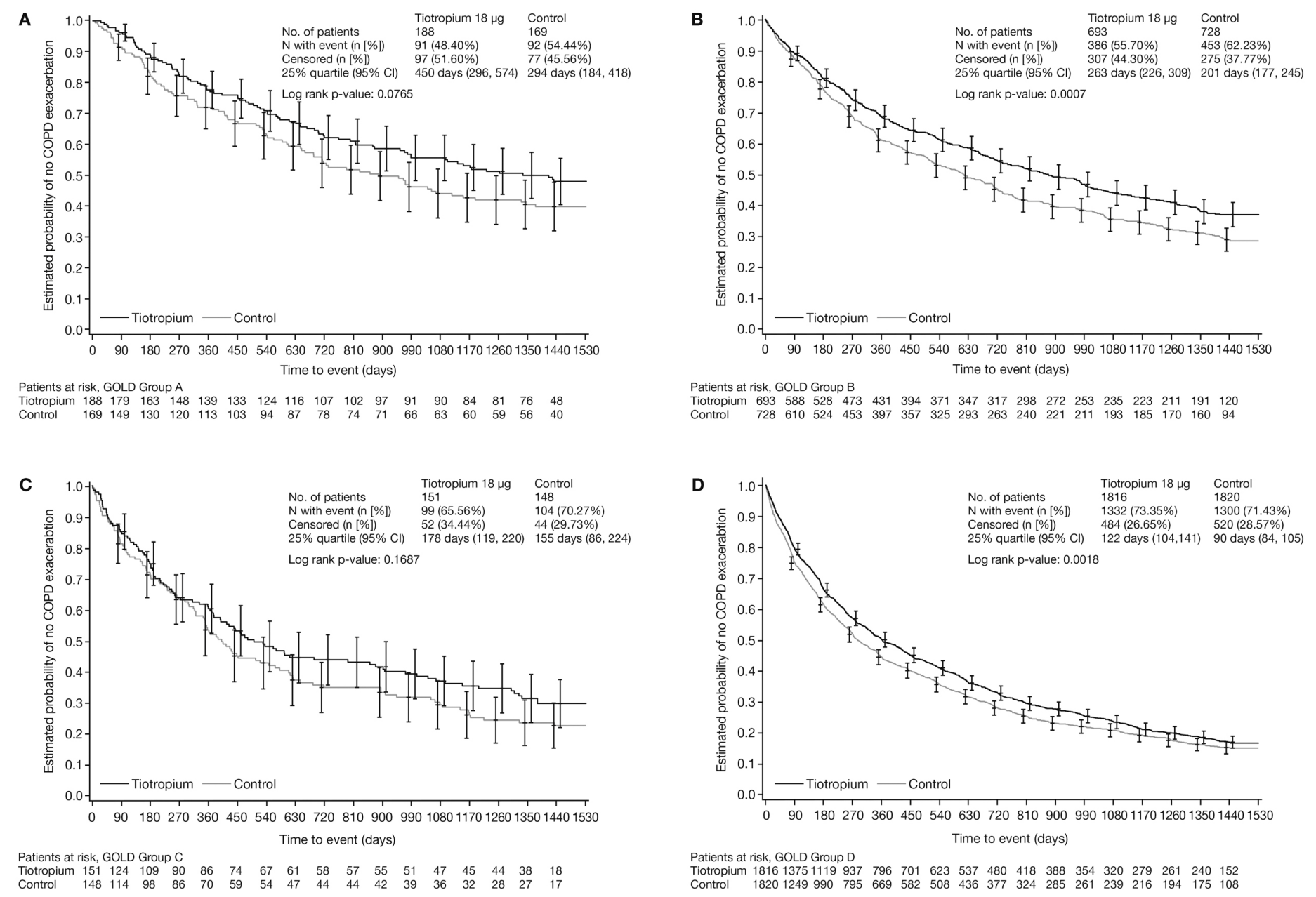

CI: confidence interval; COPD: chronic obstructive pulmonary disease; GOLD: Global initiative for chronic Obstructive Lung Disease; HR: hazard ratio; UPLIFT ${ }^{\oplus}$ : Understanding Potential Long-term Impacts on Function with Tiotropium.

\section{Discussion}

In the UPLIFT ${ }^{\circledR}$ trial, the use of tiotropium was associated with improvements in lung function and quality of life, and a reduction in the mean number of exacerbations by $14 \%(p<0.001) .{ }^{3}$ A subgroup analysis of UPLIFT ${ }^{\circledR}$ showed that in patients with GOLD Stage II (moderate) COPD, lung function, and HRQoL were better in the tiotropium group than in the control group, and tiotropium was more effective in reducing the rate of decline of postbronchodilator $\mathrm{FEV}_{1}$ and the risk of exacerbations. ${ }^{11}$

Since the publication of these results, GOLD proposed a new approach to the severity assessment of COPD that addresses both the level of symptoms and the risk of exacerbations. ${ }^{4,5}$ On the basis of this assessment scheme, the GOLD guidelines recommend long-acting anticholinergic therapy as a first-choice option for patients in GOLD Groups B, C, and D. It was, therefore, important to assess the effects of tiotropium in patients in these groups compared to usual therapy with freely prescribed respiratory medications (i.e., inhaled LABAs, ICS, and theophyllines) other than another inhaled anticholinergic agent. The analysis also gives insights into the natural history of patients with COPD, classified according to the GOLD 2013 grading system and closely monitored over 4 years.

Although the criteria for participation in the UPLIFT ${ }^{\circledR}$ trial included a diagnosis of COPD, an age of 40 years or more, a smoking history of at least 10 pack 


\section{Table 3. Rates of Fatal Adverse Events and Fatal Major Adverse Cardiac Events by GOLD Grade}

\begin{tabular}{|c|c|c|c|c|c|c|c|c|}
\hline \multirow{2}{*}{$\begin{array}{l}\text { GOLD Group } \\
\text { Treatment Group }\end{array}$} & \multicolumn{2}{|c|}{$\mathbf{A}$} & \multicolumn{2}{|c|}{ B } & \multicolumn{2}{|c|}{ C } & \multicolumn{2}{|c|}{ D } \\
\hline & Tiotropium & Control & Tiotropium & Control & Tiotropium & Control & Tiotropium & Control \\
\hline Number of patients & 188 & 169 & 693 & 728 & 151 & 148 & 1816 & 1820 \\
\hline Death (fatal AE), n (\%) & $113(6.9)$ & $11(6.5)$ & $58(8.4)$ & 72 (9.9) & $15(9.9)$ & $13(8.8)$ & $276(15.2)$ & $291(16.0)$ \\
\hline Rate per 100 patient years & 1.92 & 1.87 & 2.57 & 3.14 & 3.04 & 2.70 & 5.08 & 6.06 \\
\hline RR (tiotropium/control) & 1.03 & $.46,2.29)$ & 0.82 & $0.58,1.16)$ & 1.12 & $0.54,2.36)$ & 0.84 & $0.71,0.99)^{a}$ \\
\hline
\end{tabular}

(95\% CI)

\begin{tabular}{|c|c|c|c|c|c|c|c|c|}
\hline Fatal MACE, n (\%) & $4(2.1)$ & $3(1.8)$ & $16(2.3)$ & $21(2.9)$ & $6(4.0)$ & $4(2.7)$ & $68(3.7)$ & $86(4.7)$ \\
\hline Rate per 100 patient years & 0.59 & 0.51 & 0.70 & 0.91 & 1.20 & 0.83 & 1.23 & 1.76 \\
\hline $\begin{array}{l}\text { RR (tiotropium/control) } \\
(95 \% \mathrm{CI})\end{array}$ & \multicolumn{2}{|c|}{$1.16(0.26,5.18)$} & \multicolumn{2}{|c|}{$0.78(0.41,1.49)$} & \multicolumn{2}{|c|}{$1.45(0.41,5.14)$} & \multicolumn{2}{|c|}{$0.70(0.51,0.96)^{\mathrm{a}}$} \\
\hline Cardiac death, $\mathrm{n}(\%)$ & $0(0)$ & $0(0)$ & $0(0)$ & $0(0)$ & $0(0)$ & $0(0)$ & $0(0)$ & $1(0.1)$ \\
\hline Rate per 100 patient years & & & & & & & 0 & 0.02 \\
\hline $\begin{array}{l}\text { RR (tiotropium/control) } \\
(95 \% \mathrm{CI})\end{array}$ & & & & & & & 0 & 0 \\
\hline Stroke, $\mathrm{n}(\%)$ & $0(0)$ & $0(0)$ & $4(0.6)$ & $3(0.4)$ & $0(0)$ & $0(0)$ & $8(0.4)$ & $8(0.4)$ \\
\hline Rate per 100 patient years & & & 0.18 & 0.13 & & & 0.14 & 0.16 \\
\hline $\begin{array}{l}\text { RR (tiotropium/control) } \\
(95 \% \text { CI })\end{array}$ & & & \multicolumn{2}{|c|}{$1.36(0.30,6.08)$} & & & \multicolumn{2}{|c|}{$0.88(0.33,2.35)$} \\
\hline
\end{tabular}

\begin{tabular}{l|crrrrrrr}
\hline Cardiac disorders, $\mathrm{n}(\%)$ & $2(1.1)$ & $2(1.2)$ & $10(1.4)$ & $13(1.8)$ & $4(2.6)$ & $3(2.0)$ & $50(2.8)$ & $60(3.3)$ \\
\hline Rate per 100 patient years & 0.29 & 0.34 & 0.44 & 0.56 & 0.79 & 0.62 & 0.90 & 1.23 \\
\hline $\mathrm{RR}$ (tiotropium/control) & $0.87(0.12,6.17)$ & $0.79(0.34,1.79)$ & $1.28(0.29,5.72)$ & $0.74(0.51,1.07)$
\end{tabular}

(95\% CI)

\begin{tabular}{lrr|rrrrrr}
\hline Myocardial infarction, $\mathrm{n}(\%)$ & $2(1.1)$ & $0(0)$ & $1(0.1)$ & $1(0.1)$ & $2(1.3)$ & $1(0.7)$ & $7(0.4)$ & $17(0.9)$ \\
\hline Rate per 100 patient years & 0.29 & 0 & 0.04 & 0.04 & 0.40 & 0.21 & 0.13 & 0.35 \\
\hline RR (tiotropium/control) & & & $1.02(0.06,16.33)$ & $1.92(0.17,21.16)$ & $0.36(0.15,0.88)^{\mathrm{a}}$
\end{tabular}

(95\% CI)

\begin{tabular}{|c|c|c|c|c|c|c|c|c|}
\hline Sudden cardiac death, $n(\%)$ & $0(0)$ & $0(0)$ & $0(0)$ & $0(0)$ & $0(0)$ & $0(0)$ & $1(0.1)$ & \\
\hline Rate per 100 patient years & & & & & & & 0.02 & 0. \\
\hline $\begin{array}{l}\text { RR (tiotropium/control) } \\
(95 \% \mathrm{CI})\end{array}$ & & & & & & & \multicolumn{2}{|c|}{$0.44(0.04,4.8$} \\
\hline Sudden death, $n(\%)$ & $2(1.1)$ & $1(0.6)$ & $1(0.1)$ & $1(0.1)$ & $1(0.7)$ & $0(0.0)$ & $6(0.3)$ & \\
\hline Rate per 100 patient years & 0.29 & 0.17 & 0.04 & 0.04 & 0.20 & 0 & 0.11 & \\
\hline $\begin{array}{l}\text { RR (tiotropium/control) } \\
(95 \% \mathrm{CI})\end{array}$ & \multicolumn{2}{|c|}{$1.74(0.16,19.18)$} & \multicolumn{2}{|c|}{$1.02(0.06,16.34)$} & & & \multicolumn{2}{|c|}{$0.66(0.23,1.9$} \\
\hline Vascular disorders, $n(\%)$ & $0(0)$ & $0(0)$ & $1(0.1)$ & $4(0.5)$ & $1(0.7)$ & $1(0.7)$ & $4(0.2)$ & $10(C$ \\
\hline Rate per 100 patient years & & & 0.04 & 0.17 & 0.20 & 0.21 & 0.07 & \\
\hline $\begin{array}{l}\text { RR (tiotropium/control) } \\
(95 \% \mathrm{CI})\end{array}$ & & & \multicolumn{2}{|c|}{$0.25(0.03,2.28)$} & $0.97(C$ & 15.43) & \multicolumn{2}{|c|}{$0.35(0.11,1$. } \\
\hline \multicolumn{9}{|c|}{$\begin{array}{l}\text { Events are counted from drug start through drug stop + } 30 \text { days. } \\
\text { Time at risk is the time from drug start to the first occurrence of the event of interest but censored at min } \\
\text { (date of death, drug stop date + } 30 \text { days). } \\
\text { Fatal MACE: cardiac SOC (fatal) or vascular SOC (fatal) or sub-SMQ myocardial infarction (broad) (fatal) or PV stroke (fatal) or } \\
\text { sudden death PT or cardiac death PT or sudden cardiac death PT. MedDRA version } 16.1 \text { was used for reporting. } \\
\text { a Ratio significantly different from } 1 \text {. } \\
\text { AE: adverse event; CI: confidence interval; MACE: major adverse cardiac events; PT: preferred term; PV: polycythemia vera; } \\
\text { RR: rate ratio; SOC: system organ class. }\end{array}$} \\
\hline
\end{tabular}




\section{Table 4. Rates of Major Adverse Cardiac Events by GOLD Grade}

$\begin{array}{lcccc}\text { GOLD Group } & \text { A } & \text { B } & \text { C } & \text { D } \\ \text { Treatment Group } & \text { Tiotropium } & \text { Control } & \text { Tiotropium } & \text { Control } \\ \text { Tiotropium Control Tiotropium Control }\end{array}$

\begin{tabular}{|c|c|c|c|c|c|c|c|c|}
\hline Number of patients & 188 & 169 & 693 & 728 & 151 & 148 & 1816 & 1820 \\
\hline MACE, n (\%) & $11(5.9)$ & $12(7.1)$ & $43(6.2)$ & $57(7.8)$ & $13(8.6)$ & $12(8.1)$ & $151(8.3)$ & $168(9.2)$ \\
\hline Rate per 100 patient years & 1.66 & 2.11 & 1.93 & 2.53 & 2.66 & 2.55 & 2.80 & 3.52 \\
\hline $\begin{array}{l}\text { RR (tiotropium/control) } \\
(95 \% \mathrm{CI})\end{array}$ & \multicolumn{2}{|c|}{$0.79(0.35,1.78)$} & \multicolumn{2}{|c|}{$0.76(0.51,1.13)$} & \multicolumn{2}{|c|}{$1.04(0.48,2.28)$} & \multicolumn{2}{|c|}{$0.79(0.64,0.99)^{2}$} \\
\hline Cardiac death, $\mathrm{n}(\%)$ & $0(0)$ & $0(0)$ & $0(0)$ & $0(0)$ & $0(0)$ & $0(0)$ & $0(0)$ & $1(0.1)$ \\
\hline Cardiac disorders, $\mathrm{n}(\%)$ & $2(1.1)$ & $2(1.2)$ & $10(1.4)$ & $13(1.8)$ & $4(2,6)$ & $3(2.0)$ & $50(2.8)$ & $60(3.3)$ \\
\hline Rate per 100 patient years & 0.29 & 0.34 & 0.44 & 0.56 & 0.79 & 0.62 & 0.90 & 1.23 \\
\hline $\begin{array}{l}\text { RR (tiotropium/control) } \\
(95 \% \mathrm{CI})\end{array}$ & \multicolumn{2}{|c|}{$0.87(0.12,6.17)$} & \multicolumn{2}{|c|}{$0.79(0.34,1.79)$} & \multicolumn{2}{|c|}{$1.28(0.29,5.72)$} & \multicolumn{2}{|c|}{$0.74(0.51,1.07)$} \\
\hline Stroke, n (\%) & $5(2.7)$ & $4(2.4)$ & $15(2.2)$ & $26(3.6)$ & $4(2.6)$ & $5(3.4)$ & $54(3.0)$ & $44(2.4)$ \\
\hline Rate per 100 patient years & 0.75 & 0.69 & 0.66 & 1.14 & 0.80 & 1.05 & 0.98 & 0.91 \\
\hline $\begin{array}{l}\text { RR (tiotropium/control) } \\
(95 \% \mathrm{CI})\end{array}$ & \multicolumn{2}{|c|}{$1.09(0.29,4.06)$} & \multicolumn{2}{|c|}{$0.58(0.31,1.10)$} & \multicolumn{2}{|c|}{$0.76(0.20,2.83)$} & \multicolumn{2}{|c|}{$1.09(0.73,1.62$} \\
\hline Myocardial infarction, $n(\%)$ & $5(2.7)$ & $5(3.0)$ & $20(2.9)$ & $19(2.6)$ & $7(4.6)$ & $4(2.7)$ & $52(2.9)$ & $67(3.7)$ \\
\hline Rate per 100 patient years & 0.74 & 0.86 & 0.89 & 0.82 & 1.41 & 0.84 & 0.95 & 1.38 \\
\hline $\begin{array}{l}\text { RR (tiotropium/control) } \\
(95 \% \mathrm{CI})\end{array}$ & \multicolumn{2}{|c|}{$0.86(0.25,2.96)$} & \multicolumn{2}{|c|}{$1.08(0.57,2.02)$} & \multicolumn{2}{|c|}{$1.68(0.49,5.75)$} & \multicolumn{2}{|c|}{$0.68(0.48,0.98)^{2}$} \\
\hline Sudden cardiac death, $\mathrm{n}(\%)$ & $0(0)$ & $0(0)$ & $0(0)$ & $0(0)$ & $0(0)$ & $0(0)$ & $1(0.1)$ & $2(0.1)$ \\
\hline Rate per 100 patient years & & & & & & & 0.02 & 0.04 \\
\hline $\begin{array}{l}\text { RR (tiotropium/control) } \\
(95 \% \mathrm{CI})\end{array}$ & & & & & & & 0.44 & $.04,4.87)$ \\
\hline Sudden death, $\mathrm{n}(\%)$ & $2(1.1)$ & $1(0.6)$ & $1(0.1)$ & $1(0.1)$ & $1(0.7)$ & $0(0)$ & $6(0.3)$ & $8(0.4)$ \\
\hline Rate per 100 patient years & 0.29 & 0.17 & 0.04 & 0.04 & 0.20 & 0 & 0.11 & 0.16 \\
\hline $\begin{array}{l}\text { RR (tiotropium/control) } \\
(95 \% \mathrm{CI})\end{array}$ & \multicolumn{2}{|c|}{$1.74(0.16,19.18)$} & \multicolumn{2}{|c|}{$1.02(0.06,16.34)$} & & & \multicolumn{2}{|c|}{$0.66(0.23,1.91$} \\
\hline Vascular disorders, $n(\%)$ & $0(0)$ & $0(0)$ & $1(0.1)$ & $4(0.5)$ & $1(0.7)$ & $1(0.7)$ & $4(0.2)$ & $10(0.5)$ \\
\hline Rate per 100 patient years & & & 0.04 & 0.17 & 0.20 & 0.21 & 0.07 & 0.20 \\
\hline $\begin{array}{l}\text { RR (tiotropium/control) } \\
(95 \% \mathrm{CI})\end{array}$ & & & \multicolumn{2}{|c|}{$0.25(0.03,2.28)$} & \multicolumn{2}{|c|}{$0.97(0.06,15.43)$} & \multicolumn{2}{|c|}{$0.35(0.11,1.13)$} \\
\hline
\end{tabular}

Events are counted from drug start through drug stop +30 days.

Time at risk is the time from drug start to the first occurrence of the event of interest but censored at min

(date of death, drug stop date +30 days).

MACE: cardiac SOC (fatal) or vascular SOC (fatal) or sub-SMQ myocardial infarction (broad) (any) or PV stroke (any) or sudden death PT or cardiac death PT or sudden cardiac death PT. MedDRA version 16.1 was used for reporting.

${ }^{a}$ Ratio significantly different from 1.

AE: adverse event; CI: confidence interval; MACE: major adverse cardiac events; PT: preferred term; PV: polycythemia vera; RR: rate ratio; SOC: system organ class. 
years, a postbronchodilator $\mathrm{FEV}_{1}$ of $70 \%$ or less of the predicted value, and an $\mathrm{FEV}_{1}$ of $70 \%$ or less of the FVC, $^{3}$ the majority of patients fell into GOLD Group D. The proportion of patients categorized as Group A or C (i.e., having fewer symptoms) was lower, but data were available for a substantial number of patients (more than 650) in these groups. Higher levels of symptoms were associated with lower FEV 1 and $F E V_{1} /$ FVC ratios in high-risk but not low-risk patients. One in 5 patients in Group D had lung function impairment equivalent to GOLD Stage II, illustrating the effects of a multidimensional assessment approach.

A previous analysis of 2 population studies from Copenhagen, Denmark, including 6628 individuals with COPD, used information from medical records regarding hospital admissions and the use of oral corticosteroids and antibiotics to assess the number of exacerbations in the previous year, prebronchodilator $\mathrm{FEV}_{1}$ measurements and $\mathrm{mMRC}$ scores to classify patients into the GOLD groups as defined in the 2011 guideline update. ${ }^{12}$ The authors (Lange et al) found that $77.3 \%$ of patients were in Group A, $14.1 \%$ in Group B, $4.1 \%$ in Group C, and $4.4 \%$ in Group D. Perhaps reflecting the fact that the cohorts were recruited nearly 10 years ago, the proportion of patients on inhaled therapy with LABAs, long-acting anticholinergics, or ICS was low, with only $43.4 \%$ of patients in Group $\mathrm{D}$ on 1 or more of these therapies and only $52.5 \%$ on any inhaled therapy in this group. In accord with our findings (which utilized the GOLD 2013 group classification), Lange et al observed that the majority of the patients in Groups C and D were classified into these groups because of low FEV 1 level: $77 \%$ compared with $78 \%$ in UPLIFT ${ }^{\oplus}$. In this population study, a similar proportion of patients in Groups B, C, and D to the proportions found in patients in the UPLIFT ${ }^{\circledR}$ study had ischemic heart disease/coronary artery disease (20.7\% versus $16.3 \%, 10.3 \%$ versus $13.4 \%$, and $19.3 \%$ versus $16.5 \%$, respectively). The proportion of patients with ischemic heart disease/coronary artery disease was lower in Group A in the population study than in UPLIFT $^{\circledR}$ patients (7.0\% versus $13.2 \%$ ). It is important to note that, unlike UPLIFT ${ }^{\oplus}$, the Copenhagen analysis included patients with GOLD Stage I (mild) COPD.

In another study, based on 3633 COPD patients from 11 cohorts in Spain recruited over a period of 20 years and using only hospitalization data to assess exacerbation risk, $33.6 \%$ overall were in Group A, $16.3 \%$ were in Group B, $17.7 \%$ were in Group C, and
32.3\% were in Group D based on the GOLD 2011 classification scheme. ${ }^{13}$ There was, however, significant heterogeneity between the individual cohorts, with 4 having over $50 \%$ of their patients in Group D, with similar distributions in these clinical cohorts to our single UPLIFT ${ }^{\circledR}$ cohort (which was based on the GOLD 2013 update).

Among patients in the control group of the UPLIFT ${ }^{\oplus}$ study, exacerbation rates were highest in Group D, but the rates were similar in patients in Groups B and C. Exacerbation rates in Group A were less than half of the rates in Group D. In the Copenhagen population study, the average number of exacerbations per year in Groups A, B, C, and D over 3 years, was 0.0, 0.2, 0.6, and 0.9, respectively. ${ }^{12}$ The rates we observed were higher in Groups A and B, but similar in Groups C and D; again, this may reflect the fact that GOLD Stage I patients were included in the Copenhagen analysis.

In the Norwegian Genetics of Chronic Obstructive Lung Disease (GenKOLS) study, Johannessen and colleagues compared the 2011 and previous 2007 GOLD grading system for predicting mortality and hospitalization, and concluded that the predictive ability of the new grading system did not differ significantly from the previous one. ${ }^{14}$ This study followed 912 patients with COPD for 8 years: $20 \%$ of patients were classified in Group A, 30\% in Group B, 6\% in Group $C$, and $44 \%$ in Group D, with more patients classed as Group A and less in Group D than in our UPLIFT ${ }^{\circledR}$ cohort.

Baseline SGRQ total scores in Groups A and C of our analysis (fewer symptoms) were only just above the values found in healthy people of a similar age. ${ }^{15}$ As shown by the sensitivity analysis, SGRQ scores were higher in patients in Group D compared with those in Group B, suggesting that the impact of exacerbations on health status is greater in patients with higher levels of symptoms, particularly those who are breathless. After at least 6 months of treatment, patients in the tiotropium group also had lower SGRQ scores (indicating better health status) than patients in the control group and these differences were statistically significant. There was a difference in the change in SGRQ scores over time between patients in low- and high-symptom groups, with those in the fewer-symptom groups showing progressive worsening rather than the initial improvement seen in high-symptom patients. This may reflect the fact that it is not possible to reduce symptom levels in patients who have minimal or no symptoms at 
baseline, whereas those with a higher level of symptoms can experience a reduction in their symptoms, either as a result of taking part in the study or as a result of the addition of tiotropium, which had the greatest effect. Regression to the mean may be an alternative possible explanation for these differences.

Tiotropium significantly improved lung function in patients in all 4 GOLD groups, with similar absolute differences in pre- and postbronchodilator $\mathrm{FEV}_{1}$ and FVC in Groups B, C and D. The greatest level of improvement in FEV 1 and FVC was seen in Group A; the disparity (70 $\mathrm{mL} /$ year higher at the 4-year time point) in improvement in prebronchodilator $\mathrm{FEV}_{1}$ in Group $\mathrm{A}$ versus Group B, which had similar baseline $\mathrm{FEV}_{1}$ values, may have been influenced by the low number of patients in Group A. Patients in all GOLD groups who were treated with tiotropium also had fewer exacerbations than those in the control group, with a significant $11 \%$ reduction in high-risk patients in Group D. Low-risk patients also showed large and significant reductions in exacerbation rates: 36\% in Group A and 28\% in Group $\mathrm{B}$. Bearing in mind the importance of exacerbations in the natural history of COPD, our results suggest that therapy with tiotropium has an important role even in fewer-symptom, low-risk patients. This is supported by the recent findings of a randomized, placebo-controlled trial, in which tiotropium HandiHaler ${ }^{\circledR}$ improved lung function and patient-reported outcomes in maintenance therapy-naïve patients with GOLD stage II COPD. ${ }^{16}$

Previous evidence suggested an increased risk of mortality from cardiovascular disease in patients stratified into GOLD group B and D (versus A and C). ${ }^{12}$ We observed that the incidence of death (fatal adverse events), fatal MACE or MACE was highest in Group D, although within this group, the rates were significantly lower in patients treated with tiotropium versus control.

A potential fundamental limitation of this study is that between $47 \%$ and $66 \%$ of patients were receiving ICS at baseline, albeit at varying doses, and between $35 \%$ and $53 \%$ of patients were receiving a combination of ICS and LABAs. Thus, although patients in Group A were classified as having fewer symptoms and being at low risk, some of them may have had few symptoms or less than 1 exacerbation because of the effects of their therapy rather than being intrinsically at low risk. However, despite this, if the GOLD assessment scheme is used to decide on therapy in previously treated as well as treatment-naïve patients, the results of this analysis appear valid.
In addition to the above limitation, patients' levels of symptoms at baseline were classified using SGRQ scores rather than $\mathrm{mMRC}$ or CAT scores (as recommended by GOLD); however, in view of the close correlation between CAT scores and SGRQ and the large number of patients included in the trial, we do not believe that this has significantly influenced the results. The CAT score is a more appropriate tool than the SGRQ for use in routine clinical practice, but SGRQ is well suited for use in clinical trials and both scores have good longitudinal validity. ${ }^{15,17}$ Using different cut offs for the SGRQ results in a widely different distribution of patients among the groups, but the original intent of the GOLD revision was to emphasize a gradation across the symptom axis rather than a validated dichotomous cut-off at a particular CAT score. Classification of risk was based both on postbronchodilator $\mathrm{FEV}_{1}$ values and the number of courses of antibiotics and/or systemic corticosteroids as recalled by the patients. It is possible that their recollection was incorrect, but other studies have shown that, generally, it is accurate and appropriate to use this as an alternative to relying on health records. ${ }^{18}$

Finally, the patients who took part were selected for involvement in a clinical trial and, therefore, may not be fully representative of patients seen in practice, particularly with regard to the distribution between GOLD groups and the presence of comorbidities. It should be noted, that the inclusion and exclusion criteria were relatively liberal, recruitment included a broad selection of patients with COPD with multiple comorbidities, and patients were permitted to continue to use all prescribed respiratory medication except for anticholinergics, thus mimicking real-world conditions for pharmacotherapy. Other preliminary analyses of patient populations have shown similar distributions of patients into the GOLD groups and similar levels of cardiovascular comorbidity. ${ }^{12-14}$

In conclusion, this analysis suggests that oncedaily tiotropium improved lung function, HRQoL and exacerbation outcomes in patients in the UPLIFT ${ }^{\circledR}$ trial across all 4 GOLD 2013 severity grades (Groups A, B, $C$, and D).

\section{Acknowledgments}

The authors would like to thank Dr. Katrin Kupas for statistical support. Editorial assistance was provided by Natalie Dennis and Sarah J. Petit from PAREXEL, which was funded jointly by Boehringer Ingelheim and Pfizer. 
All authors contributed to drafting the article and critically revising the content of the manuscript, and made the decision to submit this work for publication. All authors read and approved the final manuscript.

\section{Declaration of Interest}

Dr. Inge Leimer and Dr. Norbert Metzdorf are employees of Boehringer Ingelheim. Dr. Halpin has received personal fees from Almirall, AstraZeneca, Boehringer Ingelheim, GSK, Intermune, Pfizer, Novartis, and nonfinancial support from Boehringer Ingelheim and Novartis. Dr. Tashkin has received grants or personal fees for consulting, speaking or acting on the advisory board from Boehringer Ingelheim, Novartis, Pfizer,
AstraZeneca, Forest, Sunovion, GlaxoSmithKline, and Theravance. Dr. Tashkin received grants and advisory board fees from Boehringer Ingelheim during the course of the UPLIFT study. Dr. Celli has received fees for consulting from GlaxoSmithKline, AstraZeneca, Boehringer Ingelheim, Novartis, and Medimmune. Dr. Celli was a principal investigator in the UPLIFT ${ }^{\circledR}$ study, and received grants from the St. Elizabeth's Medical Center. Dr. Decramer has received research grants or fees for consulting or speaking from Novartis, Nycomed, Boehringer Ingelheim, GlaxoSmithKline, Altana, and AstraZeneca. Editorial assistance was provided by Natalie Dennis and Sarah J. Petit from PAREXEL, which was funded jointly by Boehringer Ingelheim and Pfizer. 


\section{References}

1. Casaburi R, Mahler DA, Jones PW, et al. A long-term evaluation of once-daily inhaled tiotropium in chronic obstructive pulmonary disease. Eur Respir J. 2002;19(2):217-224. doi: http://dx.doi.org/10.1183/09031936.02.00269802

2. Celli B, ZuWallack R, Wang S, Kesten S. Improvement in resting inspiratory capacity and hyperinflation with tiotropium in COPD patients with increased static lung volumes. Chest. 2003;124(5):17431748. doi: http://dx.doi.org/10.1378/chest.124.5.1743

3. Tashkin DP, Celli B, Senn S, et al. A 4-year trial of tiotropium in chronic obstructive pulmonary disease. $N$ Engl J Med. 2008;359(15):1543-1554. doi: http://dx.doi.org/10.1056/NEJMoa0805800

4. Global Initiative for Chronic Obstructive Lung Disease (GOLD). Global strategy for the diagnosis, management, and prevention of chronic obstructive pulmonary disease: revised 2011.GOLD website. http://www.goldcopd.org/uploads/users/files/GOLD_ Report_2011_Jan21.pdf. Published 2011. Accessed November 12, 2013.

5. Global Initiative for Chronic Obstructive Lung Disease (GOLD). Global strategy for the diagnosis, management, and prevention of chronic obstructive pulmonary disease. GOLD website. http:// www.goldcopd.org/uploads/users/files/GOLD_Report_2013_ Feb20.pdf. Published 2013. Accessed November 12, 2013.

6. Mahler DA, Wells CK. Evaluation of clinical methods for rating dyspnea. Chest. 1988;93(3):580-586. doi: http://dx.doi.org/10.1378/chest.93.3.580

7. Jones PW, Harding G, Berry P, Wiklund I, Chen WH, Kline LN. Development and first validation of the COPD Assessment Test. Eur Respir J. 2009;34(3):648-654. doi: http://dx.doi.org/10.1183/09031936.00102509

8. Decramer M, Celli B, Tashkin DP, et al. Clinical trial design considerations in assessing long-term functional impacts of tiotropium in COPD: the UPLIFT trial. COPD. 2004;1(2):303-312. doi: http://dx.doi.org/10.1081/COPD-200026934

9. American Thoracic Society. Standardization of Spirometry, 1994 Update. Am J Respir Crit Care Med. 1995;152(3):1107-1136. doi: http://dx.doi.org/10.1164/ajrccm.152.3.7663792

10. Jones PW, Brusselle G, Dal Negro RW, et al. Properties of the COPD assessment test in a cross-sectional European study. Eur Respir J. 2011;38(1):29-35. doi: http://dx.doi.org/10.1183/09031936.00177210

11. Decramer M, Celli B, Kesten S, Lystig T, Mehra S, Tashkin DP. Effect of tiotropium on outcomes in patients with moderate chronic obstructive pulmonary disease (UPLIFT): a prespecified subgroup analysis of a randomised controlled trial. Lancet. 2009;374(9696):1171-1178. doi: http://dx.doi.org/10.1016/S0140-6736(09)61298-8

12. Lange P, Marott JL, Vestbo J, et al. Prediction of the clinical course of chronic obstructive pulmonary disease, using the new GOLD classification: a study of the general population. Am J Respir Crit Care Med. 2012;186(10):975-981. doi: http://dx.doi.org/10.1164/rccm.201207-12990C
13. Soriano JB, Alfageme I, Almagro P, et al. Distribution and prognostic validity of the new Global Initiative for Chronic Obstructive Lung Disease grading classification. Chest. 2013;143(3):694-702.

14. Johannessen A, Nilsen RM, Storebo M, Gulsvik A, Eagan T, Bakke P. Comparison of 2011 and 2007 Global Initiative for Chronic Obstructive Lung Disease guidelines for predicting mortality and hospitalization. Am J Respir Crit Care Med. 2013;188(1):51-59. doi: http://dx.doi.org/10.1164/rccm.201212-2276OC

15. Ferrer M, Villasante C, Alonso J, et al. Interpretation of quality of life scores from the St. George's Respiratory Questionnaire. Eur Respir J. 2002;19(3):405-413. doi: http://dx.doi.org/10.1183/09031936.02.00213202

16. Troosters T, Sciurba FC, Decramer M, et al. Tiotropium in patients with moderate COPD naive to maintenance therapy: a randomised placebo-controlled trial. NPJ Prim Care Respir Med. 2014;24:14003. doi: http://dx.doi.org/10.1038/npjpcrm.2014.3

17. Tsiligianni IG, van der Molen T, Moraitaki D, et al. Assessing health status in COPD. A head-to-head comparison between the COPD assessment test (CAT) and the clinical COPD questionnaire (CCQ). BMC Pulm Med. 2012;12:20. doi: http://dx.doi.org/10.1186/1471-2466-12-20

18. Quint JK, Donaldson GC, Hurst JR, Goldring JJ, Seemungal TR, Wedzicha JA. Predictive accuracy of patient-reported exacerbation frequency in COPD. Eur Respir J. 2011;37(3):501507. doi: http://dx.doi.org/10.1183/09031936.00035909 